\title{
Altitude and Soil Factors Gray Relational Analysis in The Dry - hot Valleys of Jinsha River
}

\author{
ZHANG XIAOXIA ${ }^{1, a}$ LI PENG $^{2, b}$ WANG YONG ${ }^{2, b}$ ZHANG DAIQING $^{1, c}$ \\ ${ }^{1}$ Power Engineering Institute, Kunming University of Science and Technology, China \\ ${ }^{2}$ Key Laboratory of North West Water Resources and Environment Ecology.Ministry of \\ Education,Xi'an University of Technology,China \\ azzxxdh@126.com, ${ }^{b}$ lipeng74@163.com, ${ }^{\mathrm{c}} 767970405 @ q q . c o m$
}

\begin{abstract}
Keywords: dry-hot valley; altitude; soil; grey correlation
Abstract. This paper analyzed the relationship between altitude and soil factors in dry - hot valley, based on gray relational grade analysis method for quantitative analysis, and Cluster analysis of the associated degree. The results showed that: altitude most closely with the available nitrogen, followed by potassium, organic matter; most unclosely is the bulk density. The close degree of relational grade between soil factors and altitude can be broadly divided into three categories.
\end{abstract}

\section{Introduction}

Soil as an important part of terrestrial ecosystem, is core area of material cycle, energy conversion and transmission of information ${ }^{[1]}$.Soil not only provide a survival habitat for animals and microbes, but also provides essential nutrition and water for plant, is the main place of various material and energy conversion ${ }^{[2]}$. The quality of soil conditions is directly related to the merits of its grown species. In affecting crop growth factor, the altitude is one of important factor. This is because changes in altitude often results in the amount of sun light, light intensity, air humidity, rainfall, temperature difference between day and night and the effective accumulated temperature and other ecological factors changed significantly ${ }^{[3-7]}$.Altitude is close relation with various meteorological factors, even plays a decisive role in part of meteorological factors ${ }^{[8-9]}$.With altitude increased, the average climate temperature continues to decreased, precipitation and sunshine hours increase, frost and $\geqslant 10{ }^{\circ} \mathrm{C}$ accumulated temperature has continued to decreased ${ }^{[7]}$, and then will have a significant influences to plant growth. Meteorological index showing a regular changes with changing altitude.

Dry - hot valley is a unique type of geography after transection southwest of deep mountain, is a sub-type of arid valley, the region's arid climate, water and heat extremely uneven. Over the years, because of copper smelting and modern reclamation of steep slopes in history and the irrational exploitation of natural resources, leading to the ecological functions of the area significant degradation under natural and human factors affecting, has become one of China's ecological environment is fragile region ${ }^{[10-12]}$.For a long time, vegetation, soil properties under different elevation were studied intensively, it has achieved abundant research results ${ }^{[13-16]}$. Despite a lot of researches, but use of gray correlation method to research altitude and soil factors in dry-hot valley has not been common reports.

Therefore, this paper use gray system theory comprehensive analysis of the relationship between altitude and soil physical and chemical properties, in order to provide evidence to the future management of soil, soil fertility directed cultivation.

\section{Study Area and Methods}

\section{Study area}

Select the study area in the east of southern Ningxia county of Jinsha River valley. The geographical position for the north latitude26 $54^{\prime}-27^{\circ} 09^{\prime}$, east longitude $102^{\circ} 54^{\prime}-103^{\circ} 02^{\prime}$, $\geqslant 10^{\circ} \mathrm{C}$ annual accumulated temperature is $7000 \sim 8000^{\circ} \mathrm{C}$, annual sunshine hours is $2179 \sim 2736 \mathrm{~h}$, belong to multi-zone sunshine; annual precipitation is between $600 \sim 800 \mathrm{~mm}$, annual evaporation is $3 \sim 6$ times 
than annual precipitation; distinct of dry and wet season. Evaporation dry season is 20 times higher than the precipitation, the serious lack of soil moisture, both relative water capacity and effective water guarantee rate is very low, soil types based mainly on weak anti-evaporation of dry red, and brown soil, red soil, purple soil, etc. The main vegetation types based mainly on dry-hot valley shrubs and savanna ${ }^{[17]}$.

\section{Sample collection}

Based on the field investigation, according to the altitude from $705 \mathrm{~m}$ to $1585 \mathrm{~m}$, selected typical grassland 7 blocks and Yunnan pine 1 block as research object ${ }^{[17]}$,basic characteristics of sample plot see table 1. Each altitude choose three plots, each plot choose seven samples according to $\mathrm{S}$ type, digging depth of $0-20 \mathrm{~cm}$ soil samples, spare after uniform mixing. After removing visible animal and plant residues and stones, soil samples was air-dried, sieved storage for analyzing measurements of soil indicators.

Table1 Basic characteristics of sample plot

\begin{tabular}{lllcccc}
\hline Land type & Terrain & Aspect & $\begin{array}{c}\text { Slope } \\
{\left[{ }^{\circ}\right]}\end{array}$ & $\begin{array}{c}\text { Altitude } \\
{[\mathrm{m}]}\end{array}$ & Soil type & $\begin{array}{c}\text { Total } \\
\text { coverage } \\
{[\%]}\end{array}$ \\
\hline Grassland & Windward slope & ES17 & 35 & 705 & Dry red soil & 70 \\
Grassland & Windward slope & NE6.5 $^{\circ}$ & 28 & 805 & Dry red soil & 20 \\
Grassland & Windward slope & ES11 $^{\circ}$ & 26 & 920 & Dry red soil & 20 \\
Grassland & Windward slope & ES & 26 & 1005 & Dry red soil & 20 \\
Grassland & Windward slope & ES16 & 30 & 1235 & Dry red soil & 20 \\
Grassland & Windward slope & WN33 & 30 & 1400 & Dry red soil & 30 \\
Grassland & Windward slope & ES16 & 26 & 1500 & Dry red soil & 20 \\
Pine forest & Windward slope & ES14 & 40 & 1585 & Dry red soil & 80 \\
\hline
\end{tabular}

\section{Determination of soil index}

Soil bulk density using cutting ring method; TOC using outside heating method of potassium dichromate oxidation, TN using Semimicro-Kjeldahl Method, $\mathrm{PH}$ using $\mathrm{pH}$ meter, TP using melted sodium carbonate-the molybdenum stibium anti method, AP using Olsen method, AK using Ammonium acetate extraction - flame photometric ${ }^{[18]}$.

\section{Data Processing}

(1) Set the reference number series

According to grey system theory, altitude and soil properties metric as a gray system(altitude as reference number series, soil indicators as the comparison number of columns ), each trait indicators seen as grey system's a factor, according to Deng Julong's ${ }^{[19]}$ method to compute the correlation of various factors

(2) Dimensionless of soil performances

Because each trait factors (raw data) is difference about dimension, uncomparable. Raw data need to make indexes being dimensionless, obtained data initial image.

(3) Absolute deviation calculation of soil properties index

(4) Soil properties index correlation coefficients is calculated, which, the value of $\xi$ is 0.5 .

(5) Calculation of the related degree.

\section{Results and Analysis}

\section{Initial value processing of soil factors and altitude original data}

Initial value processing were obtained in experiments on soil factors raw data, the results shown in Table 2. 
Table 2 Initial value processing of soil factors and altitude original data

\begin{tabular}{lclllllc}
\hline Altitude & Organic matter & TN & TP & AN & AP & AK & Bulk density \\
\hline 1.00 & 1.00 & 1.00 & 1.00 & 1.00 & 1.00 & 1.00 & 1.00 \\
1.14 & 1.05 & 0.79 & 0.80 & 0.95 & 0.73 & 1.14 & 0.98 \\
1.30 & 1.72 & 1.29 & 1.53 & 1.30 & 1.24 & 1.33 & 0.92 \\
1.43 & 1.86 & 1.92 & 1.42 & 1.94 & 1.49 & 1.48 & 0.93 \\
1.75 & 2.84 & 2.52 & 1.31 & 1.68 & 1.55 & 1.46 & 0.88 \\
1.99 & 2.38 & 2.09 & 1.49 & 1.59 & 1.46 & 1.25 & 0.94 \\
2.13 & 2.27 & 1.62 & 1.53 & 1.99 & 1.27 & 1.29 & 0.95 \\
2.25 & 2.10 & 1.62 & 1.23 & 2.31 & 1.26 & 1.33 & 0.86 \\
\hline
\end{tabular}

\section{Related degree analysis of altitude and soil physical and chemical characteristics}

Based on the gray theory, grey correlation analysis is mainly reflected in the closeness of the relationship between comparison sequence and the reference sequence which is system traits. It has been obtained by analysis that with the related degree of biggest, the more close of comparison sequence and the reference sequence, more intimate the relationship.

In the research, using 《Grey Modeling Software (Seventh Edition)》,grey correlation calculation is obtained between soil factors and altitude, the results shown in Table 5.

Table 3 Grey correlation between soil factors and altitude

\begin{tabular}{cccccccc}
\hline Incidence matrix & Organic matter & TN & TP & AN & AP & AK & Bulk density \\
Altitude & 0.73 & 0.71 & 0.69 & 0.83 & 0.71 & 0.75 & 0.57 \\
\hline
\end{tabular}

As can be seen from table 5, altitude have close relationship with $\mathrm{AN}$, the correlation degree is 0.83; followed by potassium, organic matter; most unclosely is the bulk density, the correlation degree is $0.57,0.26$ correlation degree distance with AN.

\section{Clustering analysis of grey relational grade}

Correlation degree clustering analysis on these results is given by altitude and 7 factors, from the result of the clustering analysis (Fig 1), according to close degree between altitude and each factor, 7 factors can be roughly divided into three categories: the first group includes TN、AP、TP、organic matter、AK; the second group include AN; the third group is bulk density.

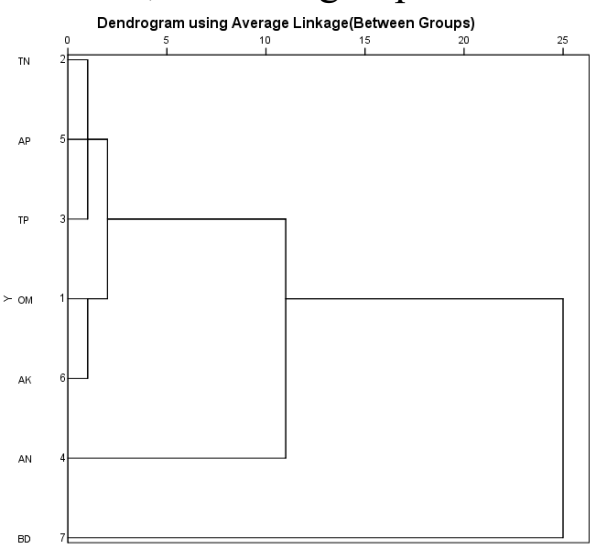

Fig 1 Ward clustering analysis of different factors

\section{Conclusion}

In this study, did not use correlation analysis, regression analysis, because these methods need a lot of sample. This article applying gray relation method, analyzes gray correlation between different soil factors and altitude. This method have hasrelatively high application value, simple and practicable, is a simple and effective practical method. 
The results showed that: altitude most closely with the available nitrogen, followed by potassium, organic matter; most unclosely is the bulk density. The close degree of relational grade between soil factors and altitude can be broadly divided into three categories.

\section{Acknowledgements}

This work was financially supported by theYunnan Training Program (KKSY201204094), the National Natural Science Foundation of China（51469009）.

\section{References}

[1] XUE Sha, LI Peng, LI Zhan-bin, eta. Soil microbial biomass and activity along an altitudinal gradient in dry-hot valley. China Environmental Science, 2011,31(11):1888 1895.

[2] TIAN Hong, ZHANG Degang, Review on the Factors Affecting the Forage Phytomass. GRASSLAND AND TURF,2003(3):15-22.

[3]NestorRosa Writied, Sunxi Fang translated. Nicotine and tobacco physiology. CHINESE TOBACCO,1984,6(2):43-46.

[4]JIANG Xiyu, XIAO Jizhong, HUANG Lidong, et al. Tobacco aroma, flavor, environment factor and ways to improve. Collection Guizhou Agri-cultural College, 1997, 4: 1-8.

[5] JIAO Jinghua, etal. Analysis and Comprehensive Evaluation on Nutrients Content Status of Tobacco Soil at Different Altitudes in Xuanen of Hubei. JOURNAL OF ANHUI AGRICULTURAL SCIENCES,2007,35(28):8936-8937,8949.

[6] LI Yanyan, LI Xihong, LI Jinping. Analysis of Climate and Soil Conditions in Enshi Tobacco-growing Areas under Different Altitudes. Journal of Hubei Institute for Nationalities (Natural Sciences), 2008,26(1):110-114.

[7] CHENG Liang, BI Qing-wen,XU Zi-cheng, et al. Effects of ecological conditions of different altitudes on quality of flue-cured tobacco in Hubei Baokang tobacco-growing regions. Journal of Zhengzhou University of Light Industry:Natural Science,2009,24(2):15-20.

[8]ZHANG Genjuan. The relationship between the topography, regional climate and its utilization on agriculture in YUNNAN. Yunnan Geographic Environment Research, 1993,5(A09):31-39.

[9] JIANG Bin et al. Research on the Key Factors of Agricultural Climate in Cultivation Division of High-quality Tobacco in Qianxinan. Journal of Anhui Agricultural Sciences, 2010, 38(18):9681-9683.

[10] YANG Wanqin, GONG Adu, HE Yurong,et al. Preliminary Investigation on Degradation Causes and Harness Approaches of Eco-environment in Dry and Hot Valley,Jinsha River-A Case from Yuanmou Region. WORLD SCI-TECH R \& D,2001,23(3):9-25.

[11] Cui Peng, Wei Fangqiang, Li Yong. Sediment transported by debris flow to the lower Jinsha river. International Journal of Sediment Research, 1999,14(4):67-71.

[12] BAI De-zhen, PAN Zhi-xian, JI Zhong-hua,et al. The problem and the countermeasures of ecological environment in Jinsha River dry valley. Territory \& Natural Resources Study, 2006,(4):50-51.

[13] ZHUANG Shunyao, LIU Guoqun, XU Mengjie,et al. Nitrogen mineralization in foreat soils varying in elevation. ACTA PEDOLOGICA SINICA, 2008, 45(6):1194-1198. 
[14] ZHOU Yan, XU Xiangen, WANG Feng, et al. Soil microbial biomass, respiration, and metabolic quotient along an altitudinal gradient in Wuyi Mountain of southeastern China. CHINESE JOURNAL OF ECOLOGY,2009,28(2):265-269.

[15] HE Qihua, HE Yonghua, BAO Weikai. Dynamics of soil water contents on south-facing slope of dry valley area in the upper reaches of the MINJIANG river. Chinese Journal of Applied and Environmental Biology ,2004,10(1):68-74.

[16] WANG Ruiyong, LIU Shasha, WANG Chengzhang, et al. Analysis on soil physicochemical indices at different altitudes in alpine rangeland. Acta Agrestia Sinica,2009,17(5): 621-628.

[17] LI Peng, LI Zhanbin, ZHENG Yu.Effect of Different Elevation on Soil Physical-chemical Properties and Erodibility in Dry-Hot Valley. Bulletin of Soil and Water Conservation,2011, 31(4):103-107.

[18]LU Rukun. Agricultural chemical analysis of soil. Beijing: China Agricultural TURE,1999:13-169.

[19] DENG Julong. Gray system and agriculture. Journl of Shanxi Agricultural Sciences, 1985(1):5-6. 